\title{
Patient with D transposition of Great Arteries Operated by Senning Procedure: A Case Report
}

\author{
Ashraful HOQUE ${ }^{1}$, Shahriar MOINUDDIN ${ }^{2}$
}

${ }^{1}$ House Surgeon, Department of cardiac Surgery, National Institute of Cardiovascular Diseases, Dhaka, Bangladesh; ${ }^{2}$ Assistant Registrar, Department of cardiac Surgery, National Institute of Cardiovascular Diseases, Dhaka, Bangladesh

[Received: 20 January 2016; Reviewed: 21 March 2016; Accepted: 31 March 2016; Published on: 1 January 2017]

\section{Abstract}

The atrial switch operation, the Mustard or Senning operation, for the transposition of the great arteries (TGA) was introduced in the late 1950s and was the preferred surgery for TGA until the early 1990s. The arterial switch operation has become the procedure of choice for patients with transposition of the great arteries (TGA) in most medical centres. Although atrial switching may occasionally be employed in some centres in cases with delayed diagnosis, pulmonary hypertension and some other unusual entities. We preferred to use the atrial switch operation Senning procedure for 5 months old child with TGA, small atrial septal defect (ASD) and patent ductus arteriosus (PDA). [Journal of Current and Advance Medical Research 2017;4(1):31-33]

Keywords: Congenital heart disease; transposition of great arteries; Senning procedure

[Cited As: Hoque A, Moinuddin S. Patient with D transposition of Great Arteries Operated by Senning Procedure: A Case Report. J Curr Adv Med Res 2017;4(1):31-33]

Correspondence: Dr. Asraful Hoque, House Surgeon, Department of cardiac Surgery, National Institute of Cardiovascular Diseases, Sher-e-Bangla Nagar, Dhaka, Bangladesh; Email: dr_asraf_sium@yahoo.com; Cell No.: +8801720834878

Conflict of Interest: None

Contributions to authors: AH \& SM have involved in the, history taking, patient management as well as the manuscript writing. Copyright: @2017 Hoque A \& Moinuddin. Published by Journal of Current and Advance Medical Research. This article is published under the Creative Commons CC BY-NC License (https://creativecommons.org/licenses/by-nc/4.0/). This license permits use, distribution and reproduction in any medium, provided the original work is properly cited, and is not used for commercial purposes.

\section{Introduction}

Transposition of the great arteries (TGA) is a common but serious congenital heart malformation, with an incidence of about 1 per 5,000 live births ${ }^{1}$. Until the late 1950s, this lesion was uniformly fatal, with most infants dying before the age of 1 year $^{2}$. The development of the Senning and Mustard atrial level repairs, however, led to good immediate outcomes and long term survival.

This procedure, a form of atrial switch, was developed and first performed by Senning in 1957 as a treatment for d-TGA (dextro-Transposition of the great arteries) before improvements in cardiopulmonary bypass made more curative surgical techniques feasible ${ }^{3}$.

With the Senning surgical repair, a baffle or conduit is created within the atria that reroutes the deoxygenated blood coming from the inferior and superior venae cavae to the mitral valve and therefore to the pulmonary circulation ${ }^{4}$. This is accomplished by creating a systemic venous conduit that channels deoxygenated blood from the superior and inferior vena cava towards the mitral valve. After this complex plastic reconstruction using flaps from the right atrial tissue and the interatrial septum and lets the oxygenated pulmonary venous blood flow to the tricuspid valve and from there to the systemic circulation. The 
anatomic left ventricle continues to pump into the pulmonary circulation and the anatomic right ventricle will work as the systemic pump, in other words the ventriculo-arterial mismatch is left unrepaired.

In the Senning's operation, atrial tissue is used to create the baffle. No prosthetic material is introduced. A complex work of incising and refolding of the native atrial tissue - which is so technically complex that has been referred to as "origami", is necessary to build the venous baffle. Indeed the Senning technique was difficult to reproduce and was not widely embraced. In this article we describe a cases in which Senning procedure was done to correct D-Transposition of great arteries with PDA and ASD in a 5 months female baby.

\section{Case Presentation}

A 5 months female baby, hailing from Shirajdikhan, Munsiganj district of Bangladesh admitted to National Institute of Cardiovascular Diseases, Dhaka, Bangladesh institute with the complaints of bluish discoloration of tongue, lips and fingernails for 4 months. Furthermore repeated attack of fever, cough and respiratory distress were also present which were associated with chest in drawing and reluctant to feed for same duration. There was no history of hemoptysis, syncope, convulsion, cyanotic spell, leg swelling or other extra cardiac congenital defects. On examination body built was below average (weight $4 \mathrm{~kg}$ ). Patient was neither icteric nor anemic. Cyanosis and clubbing were present; pulse was 132/min; BP was $80 / 40 \mathrm{~mm} \mathrm{Hg}$, respiratory rate was 40 breaths $/ \mathrm{min}$. On precordial examination there was no visible apex beat, apical impulse palpable at left $5^{\text {th }}$ intercostal space along mid clavicular line. First heart sound and second heart sound was normal. Continuous murmur best heard at left $2^{\text {nd }}$ intercostal space, grade $3 / 6$, no radiation. No pericardial rub. Other system revealed no abnormality. Chest X-Ray P/A view showed narrow superior mediastinum with plethoric lung fields and Cardiac shadow is enlarged in transverse diameter (Figure I). Echocardiography revealed DTransposition of great arteries. Pulmonary artery was coming out from LV and aorta was coming out from RV. A large PDA seen (size-3.0 mm) with left to right shunt, non-restrictive. A small ASD is seen $(2.5 \mathrm{~mm})$ with left to right shunt, non-restrictive. PASP was $35 \mathrm{mmHg}$. Severe right ventricular hypertrophy was seen with regressed left ventricular posterior wall. Intraventricular septam was intact. No coarctation, no intracardiac mass or vegetation was seen. Valves and other tracts were normal. No pericardial effusion was seen (Figure II).

It had been planned for Senning procedure to correct these deformities. With all aseptic precaution midline sternotomy was done and DTransposition of great arteries was found with anterior-posterior relation of aorta and pulmonary trunk. Then, aortic and bicaval cannulation were done. PDA ligation done and CPB was established. Heart was arrested with cardioplegic solution; then 2 parallel incisions was given; one at the RA and another one at LA just in front of pulmonary veins.

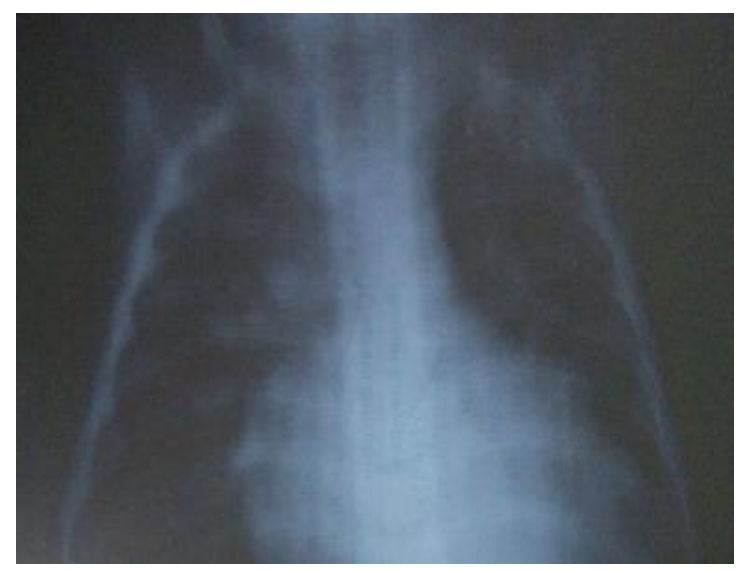

Figure I: Chest X-Ray P/A view showed narrow superior mediastinum with plethoriclung fields and Cardiac shadow is enlarged in transverse diameter

RA flap was created. An incision was made over the IAS and made $1^{\text {st }}$ layer of baffle with Dacron patch from IAS to LA auricle. Then SVC and IVC blood divert to mitral valve by making a baffle. Anastomosis of medial RA flap with LA as a result pulmonary venous blood divert to Tricuspid valve. Weaning from CPB was smooth and patient was shifted to Cardiac ICU intubated, ventilated with haemodynamically stable condition. Patient was extubated after 24 hours and was shifted to the ward on the $9^{\text {th }}$ POD.

\section{Discussion}

The arterial switch operation has become the procedure of choice for patients with TGA in most cardiac surgery centres ${ }^{5-6}$. In cases of delayed diagnosis and complicated with high pulmonary hypertension, when arterial switch operation is contraindicated, only atrial switch is the best option for patient.

Surgical intervention for TGA predates the invention of cardiopulmonary bypass. In 1950, Blalock and Hanlon described the first palliative 
procedure to surgically excise the atrial septum, thereby improving mixing and arterial saturation. With early bypass techniques, Senning performed the first 'complete' repair for TGA in $1957^{7}$. In the Senning repair, a baffle is created within the atria that redirects the deoxygenated caval blood to the mitral valve and the oxygenated pulmonary venous blood to the tricuspid valve. The anatomic left ventricle continues to act as the pulmonary pump and the anatomic right ventricle acts as the systemic pump.

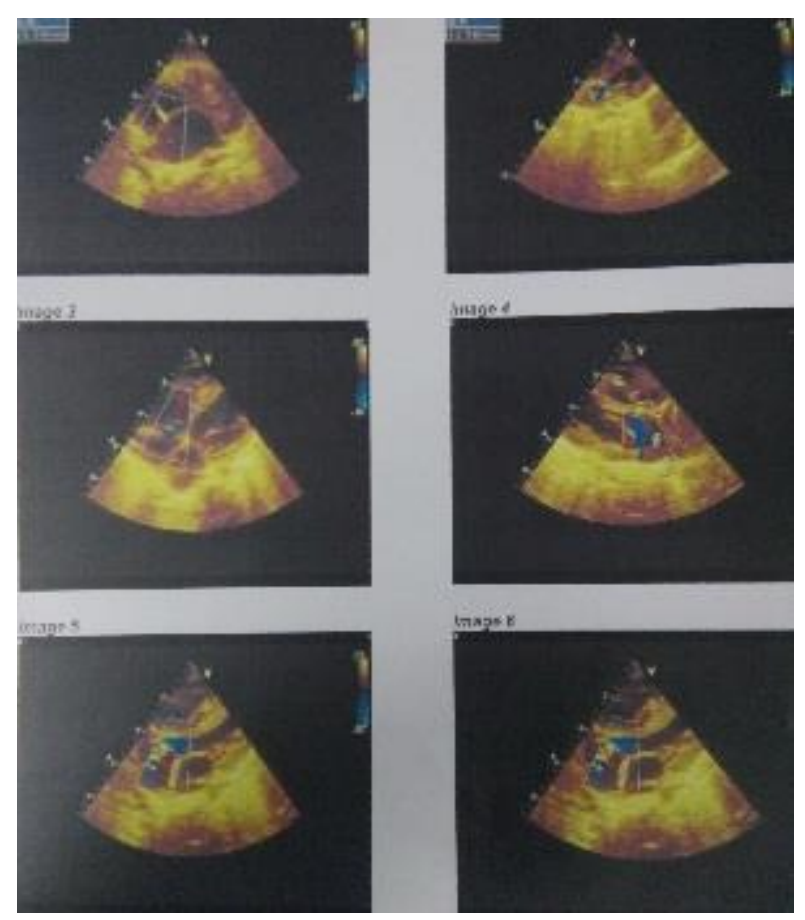

Figure II: Echocardiography revealed D-Transposition of great arteries. A large PDA seen (size-3.0 mm) with left to right shunt, non-restrictive. A small ASD is seen $(2.5 \mathrm{~mm})$ with left to right shunt, non-restrictive

In Senning's operation, complicated 'origami-style' cutting and folding of the native atrial tissue is required to achieve the venous baffle.

Owing to its complexity, the Senning technique was initially not widely embraced. The Senning procedure was revived by many surgeons in the mid-1970s ${ }^{8}$. Brom pioneered the revival of the original Senning operation, with some technical modifications, and this restored interest in this type of venous switching ${ }^{9-10}$. Surgical advances resulted in atrial-level repairs being performed in increasingly younger infants, with 1-year survival rising to more than $90 \%$ by the early 1980 s. Troubling late sequelae of atrial-level repairs were, however, becoming increasingly apparent, including atrial arrhythmias, baffle obstructions, and systemic right ventricular dysfunction, leading to a late decline in survival ${ }^{11}$.

In this case, 2 parallel incisions were given; one at the RA and another one at LA just in front of pulmonary veins. RA flap created. An incision was made over the IAS and made $1^{\text {st }}$ layer of baffle with Dacron patch from IAS to LA auricle. Then SVC and IVC blood divert to mitral valve by making a baffle. Anastomosis of medial RA flap with LA was made; as a result pulmonary venous blood was diverted to tricuspid valve.

\section{Conclusion}

The arterial switch operation has become the procedure of choice for patients with transposition of the great arteries (TGA) in most medical centres. Although atrial switching may occasionally be employed in some centres in cases with delayed diagnosis, pulmonary hypertension and some other unusual entities. We preferred to use the atrial switch operation Senning procedure for 5 months old child with TGA, small atrial septal defect (ASD) and patent ductus arteriosus (PDA).

\section{References}

1. Fyler DC. Report of the New England regional infant cardiac program. Pediatrics 1980;65 (suppl): 376-461

2. Liebman J. Natural history of transposition of the great arteries: anatomy and birth and death characteristics. Circulation 1969;40: 237-262

3. Konstantinov IE, Alexi-Meskishvili VV, Williams WG et al. Atrial Switch Operation: Past, Present, and Future. Ann Thorac Surg 2004;77:2250-8

4. Khatami A, Kadner, A, Berger F, et al. In the Footsteps of Senning: Lessons Learned From Atrial Repair of Transposition of the Great Arteries. Ann Thorac Surg 2005;79:1433-1444

5. Jonas RA, Laussen P. Transposition of the great arteries. In: Comprehensive surgical management of congenital heart disease. Hodder Arnold Publication 2007;256-279

6. Mee LB. The arterial switch operation // In: surgery for congenital heart defects. 3 rd edition by Stark J, de Leval M, Tsang V. 2006, Jonh wiley and sons Ltd 2006; 471-487

7. Senning A. Surgical correction of transposition of the great vessels. Surgery 1959;45: 966-980.

8. Wells WJ, Blackstone EH. Intermediate outcome after Mustard and Senning procedures: a study by the Congenital Heart Surgeons Society. Semin Thorac Cardiovasc Surg Pediatr Card Surg Annu 2000;3:186-197

9. Ilbawi MN, DeLeon SY, Backer CL. An alternative approach to the surgical management of physiologically corrected transposition with ventricular septal defect and pulmonary stenosis or atresia, J Thorac Cardiovasc Surg 1990;100: 410-415

10. Karl TR, Weintraub RG, Brizard CP. Senning plus arterial switch operation for discordant (congenitally corrected) transposition, Ann Thorac Surg 1997;64:495-502

11. Jatene AD. Anatomic correction of transposition of the great arteries. J Thorac Cardiovasc Surg 1982;83: 20-26 